\section{Pulmonary Response of Fifth Component of Complement-sufficient and -deficient Mice to Hyperoxia}

\author{
Debra A. Parrish, Brenda C. Mitchell, Peter M. Henson, \\ and Gary L. Larsen \\ Department of Pediatrics, National Jewish Hospital and Research \\ Center/National Asthma Center, and Department of Pediatrics, \\ Medicine, and Pathology, School of Medicine, University of \\ Colorado, Denver 80206
}

A C5, can form fragments that cause neutrophil chemotaxis, oxygen radical production, and lysosomal enzyme release. The purpose of this study was to determine if C5 and these fragments contribute to the inflammation seen in pulmonary oxygen toxicity as defined by histology and analysis of bronchoalveolar lavage fluid (BALF). In addition, the role of $\mathrm{C} 5$ in producing mortality in the animals was addressed. Pairs of $\mathrm{C} 5$ deficient (C5-) and C5 sufficient $(\mathrm{C} 5+)$ mice, 6 mo or older, were placed in a chamber and challenged with $95 \%$ oxygen at ambient pressure. A significant difference in mortality was observed after $200 \mathrm{~h}$ of exposure, i.e., $90 \%$ mortality in C5+ mice vs. $25 \%$ mortality in C5- mice $(P<0.001)$. This difference in mortality was not seen when C5mice were transfused with plasma that contained C5 derived from $\mathrm{C5}+$ mice. Morphometric analysis of histologic sections with light microscopy revealed earlier pathologic changes in $\mathrm{C} 5+$ mice that was characterized by increased cellularity due in part to neutrophil influx into the alveolar-capillary wall. Transmission electron microscopy also confirmed an earlier inflammatory response in the C5+ mice with evidence of injury to alveolar epithelial cells, interstitial edema, and an increase in the cellular component of the interstitium. Analysis of BALF also demonstrated earlier abnormalities in C5+ mice, which included a significantly greater percentage of neutrophils in the $\mathrm{C} 5+$ mice at $117 \mathrm{~h}$. Similar studies

This work was presented in part at the Annual Meeting of the American Thoracic Society, Los Angeles, May 1982.

Address reprint requests to Dr. Larsen.

Received for publication 18 October 1982 and in revised form 24 April 1984.

J. Clin. Invest.

(C) The American Society for Clinical Investigation, Inc.

0021-9738/84/09/0956/10 $\$ 1.00$

Volume 74, September 1984, 956-965 in younger mice of these strains again showed earlier neutrophil accumulation in C5+ mice, but the time course of the injury was more protracted. This study shows that the presence of $\mathrm{C5}$ is associated with a greater mortality and an earlier influx of neutrophils into murine lungs. However, in the absence of C5, neutrophils will still immigrate into the lung and hyperoxic damage will occur at a later time point, which demonstrates the inherent redundancy of the inflammatory process.

\section{Introduction}

Proteins of the complement system, including the fifth component of complement (C5), ' have been found in the bronchoalveolar lavage fluid (BALF) from normal animals $(1,2)$ and man (3). A role for complement, and C5 in particular, in pulmonary inflammation has been suggested in both immunologic and nonimmunologic lung disease (4-11). Fragments of $\mathrm{C} 5$ have been shown to be involved in the early immigration of neutrophils into murine lungs after challenge with immune complexes and Pseudomonas aeruginosa $(7,11)$. In addition, injury to cells in the lung has been shown to occur when C5 fragments have been administered to the air spaces of the lung with subsequent immigration of neutrophils into the alveoli $(5,12)$.

As in other examples of pulmonary inflammation and lung injury, early accumulation of neutrophils has been noted in oxygen toxicity $(13,14)$. A recent study of hyperoxia in rats demonstrated that an increase in lung lavage chemotactic activity was associated with increased neutrophils in BALF and the onset of mortality (15). The study also demonstrated no difference in the neutrophil accumulation when serum

1. Abbreviations used in this paper: BALF, bronchoalveolar lavage fluid; C5, the fifth component of complement; C5+, C5-sufficient B10.D2/nSn mice; C5-, C5-deficient B10.D2/oSn mice; C5a, the C5 fragment with anaphylatoxin activity; $\mathrm{C} 5 \mathrm{a}$ des Arg, the C5 fragment formed by removal of the C-terminal arginine from C5a; CoF, cobra venom factor. 
complement was depleted by cobra venom factor (CoF) before hyperoxic exposure. However, because the depletion of complement with $\mathrm{CoF}$ is neither complete nor sustained and may not affect $\mathrm{C} 5$ in the lung, this study may not have ruled out involvement of pulmonary $\mathrm{C5}$ in the development of hyperoxic lung injury.

The present study was done to determine if there is a role for $\mathrm{C} 5$ in the pathogenesis of pulmonary oxygen toxicity. The results showed increased mortality and earlier immigration of neutrophils into the lung in C5-sufficient mice as compared with congenic $\mathrm{C} 5$-deficient mice.

\section{Methods}

Animals. Congenic C5-deficient B10.D2/oSn (C5-) mice and C5sufficient B10.D2/nSn (C5+) mice were obtained from Jackson Laboratories, Bar Harbor, ME. All mice were greater than $10 \mathrm{wk}$ old when studied. Only males were used because of reports of intermediate C5 levels in females of this strain (16). To determine if the pulmonary susceptibility to oxygen changed with increasing age, two age groups of mice were examined. Mature mice were defined as being 6 mo or older on the basis of lack of somatic growth beyond this time point. Mice $2 \frac{1}{2}-31 / 2$ mo old were used as a younger comparison group. All mice were assayed to confirm their C5 status by immunodiffusion with goat anti-human C5 (Meloy Laboratories, Inc., Springfield, VA). A precipitin band was clearly noted when serum from $\mathrm{C} 5+$ mice was assayed, whereas no band was seen for C5- mice. The National Research Council's guide for the care and use of laboratory animals was followed in this study (16a).

Exposure to hyperoxia. A cylindrical chamber $96-\mathrm{cm}$ long and 56 $\mathrm{cm}$ in diameter was connected to a continuous source of oxygen, which was introduced into the chamber at a flow of 3 liters/minute. A small outlet port remained open to maintain the pressure at atmospheric pressure. A manometer was used to monitor pressure in the chamber at all times. All experiments were performed at Denver's ambient pressure (mean $=635 \mathrm{mmHg}$ ). Frequent analysis of the ambient gas mixture with a mass spectrometer (Perkin-Elmer Corp., Aerospace Div., Pomona, CA) showed that the inspired oxygen concentration was at least $95 \%$ and the $\mathrm{CO}_{2}$ was $<1 \%$ throughout the experiments. Because of Denver's low ambient pressure compared with atmospheric pressure at sea level, the challenge was comparable to an exposure to $\sim 80 \%$ oxygen at sea level.

Mortality. To determine if the presence of $\mathrm{C} 5$ affected the mortality that is associated with oxygen toxicity, pairs of $\mathrm{C5}-$ and $\mathrm{C} 5+$ mice, 6 mo or older, were placed in the chamber and challenged with $95 \%$ oxygen at ambient pressure. Mice were provided with standard laboratory chow and water ad lib. The mice were observed daily to quantitate the cumulative mortality. The hyperoxic challenge was continued for at least $200 \mathrm{~h}$ and was interrupted for a maximum of $15 \mathrm{~min}$ every $36-48 \mathrm{~h}$ to change the animal litter and provide fresh water.

Histologic examination: light microscopy. In separate studies, at various time points, the mice were removed from the oxygen and killed with an intraperitoneal injection of sodium pentobarbital (Nembutal, Abbott Laboratories, North Chicago, IL). The lungs were removed from the thoracic cavity of the mouse and inflated with $10 \%$ neutral buffered formalin at $25 \mathrm{~cm} \mathrm{H}_{2} \mathrm{O}$. When the lungs were fully inflated, the trachea was tied off. The inflated lungs were submerged in $10 \%$ formalin solution overnight. Thin sections $(5 \mu \mathrm{m})$ were taken at random from areas of the right and left lung and were stained with hematoxylin and eosin for routine histologic examination.

Morphometrics: alveolar cellularity. In lungs that were subjected to morphometric analysis, the lungs were inflated with $10 \%$ neutral buffered formalin at a constant transpulmonary pressure of $25 \mathrm{~cm}$ $\mathrm{H}_{2} \mathrm{O}$ for $36 \mathrm{~h}$. Both before and after fixation, the inflated lung volume was measured by water displacement. Midsagittal slices were cut, and blocks that were taken at random from lung slices were processed into $5-\mu$ sections and stained with hematoxylin and eosin. After cutting and before further processing, the blocks were photographed at known magnifications. The areas of the photographs and the areas of the slides were measured so that linear shrinkage during processing could be calculated as outlined by Berend et al. (17). A systematic random sampling method was used to obtain fields to analyze. A point-line grid with $\mathbf{4 2}$ points was used to select alveoli for analysis. Alveoli that were to the right and/or above the intersecting point were counted for total nuclei and polymorphonuclear nuclei. Four fields from each lung were analyzed for each animal studied.

Electron microscopy. After removal from the animals, the lungs were inflated at $25 \mathrm{~cm} \mathrm{H} \mathrm{H}_{2} \mathrm{O}$ with $1.5 \%$ glutaraldehyde in $0.1 \mathrm{M}$ cacodylate buffer at pH $7.3(\operatorname{mos} M=330)$. The trachea was tied off, and the lungs left in fixative solution overnight. Selected areas were taken for electron microscopic examination.

The tissue was postfixed in $1 \%$ osmium tetroxide in $0.1 \mathrm{M}$ cacodylate buffer, $\mathrm{pH} 7.3$, at $4^{\circ} \mathrm{C}$ for $1 \mathrm{~h}$. En bloc $1 \%$ uranyl acetate staining was performed, and then tissues were dehydrated in alcohol, cleared in propylene oxide, and infiltrated with Epon/Araldite overnight. The tissues were embedded in Epon/Araldite and cured for $72 \mathrm{~h}$ at $70^{\circ} \mathrm{C}$. Sections were cut on an Ultrotome III (LKB Instruments, Inc., Rockville, MD), and stained with $2 \%$ aqueous uranyl acetate and Reynold's lead stain. The sections were examined in a 400T electron microscope (Philips Electronic Instruments, Inc., Mahwah, NJ) at an accelerating voltage of $60 \mathrm{~V}$.

Pulmonary lavage and bronchoalveolar fluid analysis. The C5and $\mathrm{C5}+$ mice that were greater than 6 mo old were challenged with hyperoxia by the method described above. Up to 8 pairs of mice were removed after 68,117 , or $166 \mathrm{~h}$ of exposure for examination of BALF. Young C5+ and C5- mice, $2 \frac{1}{2}-3 \frac{1}{2}$ mo old, were challenged with hyperoxia in groups of 24-38 and had BALF analyzed after similar time periods plus after $215 \mathrm{~h}$ of hyperoxic exposure. After the mice were killed with an intraperitoneal injection of sodium pentobarbital, the trachea was exposed and cannulated with a sterile PE 50 polyethylene tube (Clay-Adams, Parsippany, NJ) that was attached to a 21-gauge needle. The lungs were lavaged with six $1-\mathrm{ml}$ aliquots of sterile normal saline until $5 \mathrm{ml}$ of lavage fluid was obtained. The lavaged cells were centrifuged at room temperature for $10 \mathrm{~min}$ at $180 \mathrm{~g}$. The supernatant was removed and the pellet was resuspended in $1 \mathrm{ml}$ of normal saline. The total number of leukocytes was determined within $1 \mathrm{~h}$ after lavage by using a Coulter Counter (Coulter Electronics, Inc., Hialeah, FL) after erythrocyte lysis. Preliminary studies showed that total leukocytes determined by the Coulter technique and by manual counting with a hemocytometer both gave almost identical results in both strains of mice before and after challenge. Differential cell counts ( 200 cells) were determined on Wright-stained smears from a cytospin of the cell suspension.

Cultures. To rule out bacterial infection in the lungs as a cause of death, the supernatant of the BALF was cultured on blood-agar plates. The plates were observed for bacterial growth for $72 \mathrm{~h}$.

Peripheral leukocyte counts. At the time of killing the mice for 
BALF analysis, blood was obtained from the retro-orbital plexus to determine the peripheral white blood cell count and differentials.

Transfusion of C5- mice with C5+ plasma. To determine if the differences in the response of the two strains of mice could be abolished by restoring $\mathrm{C} 5$ activity in the deficient strain, $20 \mathrm{C5}-$ mice were transfused with pooled plasma from $\mathrm{C} 5+$ mice and then subjected to hyperoxia with determination of cumulative mortality, as noted above. The plasma used in the transfusions was obtained by direct cardiac puncture of C5+ mice immediately after they were killed with an intraperitoneal injection of sodium pentobarbital. Sodium citrate was used as the anticoagulant. The transfused C5- mice received $0.5 \mathrm{ml}$ of C5+ plasma intravenously and $0.5 \mathrm{ml}$ intraperitoneally on the day before oxygen exposure, and received an additional $0.5 \mathrm{ml}$ of $\mathrm{C5}+$ plasma intraperitoneally every $48 \mathrm{~h}$ throughout the experiment. 20 C5 + mice were challenged at the same time so that cumulative mortality could be directly compared. To control for the effects of transfusion, $20 \mathrm{C5}-$ mice were transfused in an identical protocol with pooled C5- plasma, and subjected to the hyperoxic challenge with the two groups described above.

Statistical analysis. The BALF data were analyzed by using the paired or unpaired $t$ test, whereas mortality data were evaluated with a chi-square analysis with Yate's correction (18). Estimates of variance in the text, table, and figures are in standard errors.

\section{Results}

Mortality. Initially, the mortality associated with oxygen toxicity was determined in the presence or absence of C5. 20 pairs of C5- and C5+ mice were exposed to hyperoxia at ambient pressure. As shown in Fig. 1, mortality was first noted in C5+ mice at $120 \mathrm{~h}$ and in C5- mice at $150 \mathrm{~h}$. By $200 \mathrm{~h}$ of exposure, a significant difference in mortality was observed, i.e., $90 \%$ mortality in C5+ mice vs. $25 \%$ mortality in C5- mice $(P$ $<0.001)$. This difference in mortality suggested a role for $\mathrm{C5}$ in the pathogenesis of oxygen toxicity.

Histologic examination. Because the mortality data suggested that the presence of C5 increased the mortality of the mice, histologic examination of the lungs was used to evaluate how C5 might be contributing to hyperoxic lung injury. 22 pairs of C5- and C5+ mice greater than 6 mo old were challenged with hyperoxia. To evaluate early lung injury associated with hyperoxic exposure, pairs of $\mathrm{C} 5-$ and $\mathrm{C} 5+$ mice were killed for histologic examination with light microscopy after both 60 and $120 \mathrm{~h}$ of exposure. Earlier pathologic

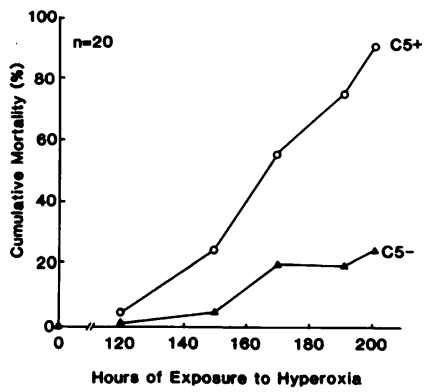

Figure 1. Percent cumulative mortality in $\mathrm{C5}+$ and $\mathrm{C5}-$ mice after prolonged exposure to hyperoxia. By $200 \mathrm{~h}$ of exposure, the cumulative mortality was significantly greater in the $\mathrm{C} 5+$ mice $(P<0.001)$. changes were noted in the $\mathrm{C} 5+$ mice, which were characterized by increased cellularity and widening of the alveolar-capillary wall. In addition, neutrophils were noted to be associated with the alveolar wall and to lie free within the alveoli in the C5+ mice at $120 \mathrm{~h}$. Examples of the changes in the mice after 60 and $120 \mathrm{~h}$ of exposure are demonstrated in Fig. 2. These changes suggest that the role of $\mathrm{C} 5$ in hyperoxic lung injury may be related to an earlier neutrophil influx into the lungs of the $\mathrm{C} 5+$ mice.

Electron microscopy. To further define the pathologic alterations produced by the oxygen exposure, transmission electron microscopy was performed on lung tissue of $\mathrm{C} 5+$ and C5- mice. The time points examined included 72,120 , and $168 \mathrm{~h}$ of exposure. In addition, tissue from both strains of mice that were exposed only to ambient air in the exposure chamber for comparable periods of time was examined as a control. In these control animals, no difference in lung structure was apparent between the strains, and in terms of the architecture of the alveolar-capillary membrane, both exhibited thin, delicate capillary endothelial and epithelial cell walls, occasional interstitial cells that were mononuclear and not polymorphonuclear, and no evidence of interstitial edema. The earliest pathologic alterations were again noted in the C5 + mice. As shown in Fig. 3, while the alveolar-capillary wall usually appeared completely normal after 72 or $120 \mathrm{~h}$ of hyperoxia in the $\mathrm{C} 5-$ mice (Fig. 3, upper right), the $\mathrm{C} 5+$ mice had evidence of interstitial edema and damage to epithelial cells (Fig. 3, bottom left and right). In addition, neutrophil accumulation in the capillaries and/or interstitium was noted. Similar findings were found in $\mathrm{C5}-$ mice at the 168-h time point; the differences in $\mathrm{C} 5+$ and $\mathrm{C5}-$ mice were not the character of the abnormalities, but the times at which they were noted.

$B A L F$. Another method for evaluating neutrophil immigration into the lung is by analysis of BALF. 37 pairs of C5and $\mathrm{C} 5+$ mice 6 mo or older were exposed to hyperoxia. After 68,117 , or $166 \mathrm{~h}$ of hyperoxic exposure, eight pairs of mice were killed and lavaged, except where specified in the text. In control animals, i.e., those that had not been exposed to hyperoxia, the total mean leukocyte counts in BALF were 4.0 $\times 10^{5}$ in $\mathrm{C} 5+$ mice vs. $4.75 \times 10^{5}$ in $\mathrm{C} 5-$ mice. In both groups, neutrophils represented $<1 \%$ of the total cells, with the remainder being mononuclear cells. After exposure to hyperoxia, the number of leukocytes in the lavage fluid increased in both $\mathrm{C} 5-$ and $\mathrm{C} 5+$ mice (Fig. 4). By $166 \mathrm{~h}$ of hyperoxia, the lavage leukocyte count in C5- compared with $\mathrm{C} 5+$ mice was $8.7 \times 10^{5}$ vs. $13.4 \times 10^{5}$, respectively. As shown in Fig. 4, the percentage of neutrophils was also noted to increase. There was a significantly greater percentage of neutrophils in the C5+ mice at $117 \mathrm{~h}(4.7 \pm 1.9 \%$ vs. $1.4 \pm 0.4 \%, P$ $<0.05$ ). By $166 \mathrm{~h}$, the mean percentage of neutrophils in $\mathrm{C} 5+$ and C5- mice was 56.2 and $24.7 \%$, respectively.

Pulmonary lavages were also done on younger mice $\left(2 \frac{1 / 2-}{}\right.$ $3^{1 / 2}$ mo old) to determine if there was a change in the response 

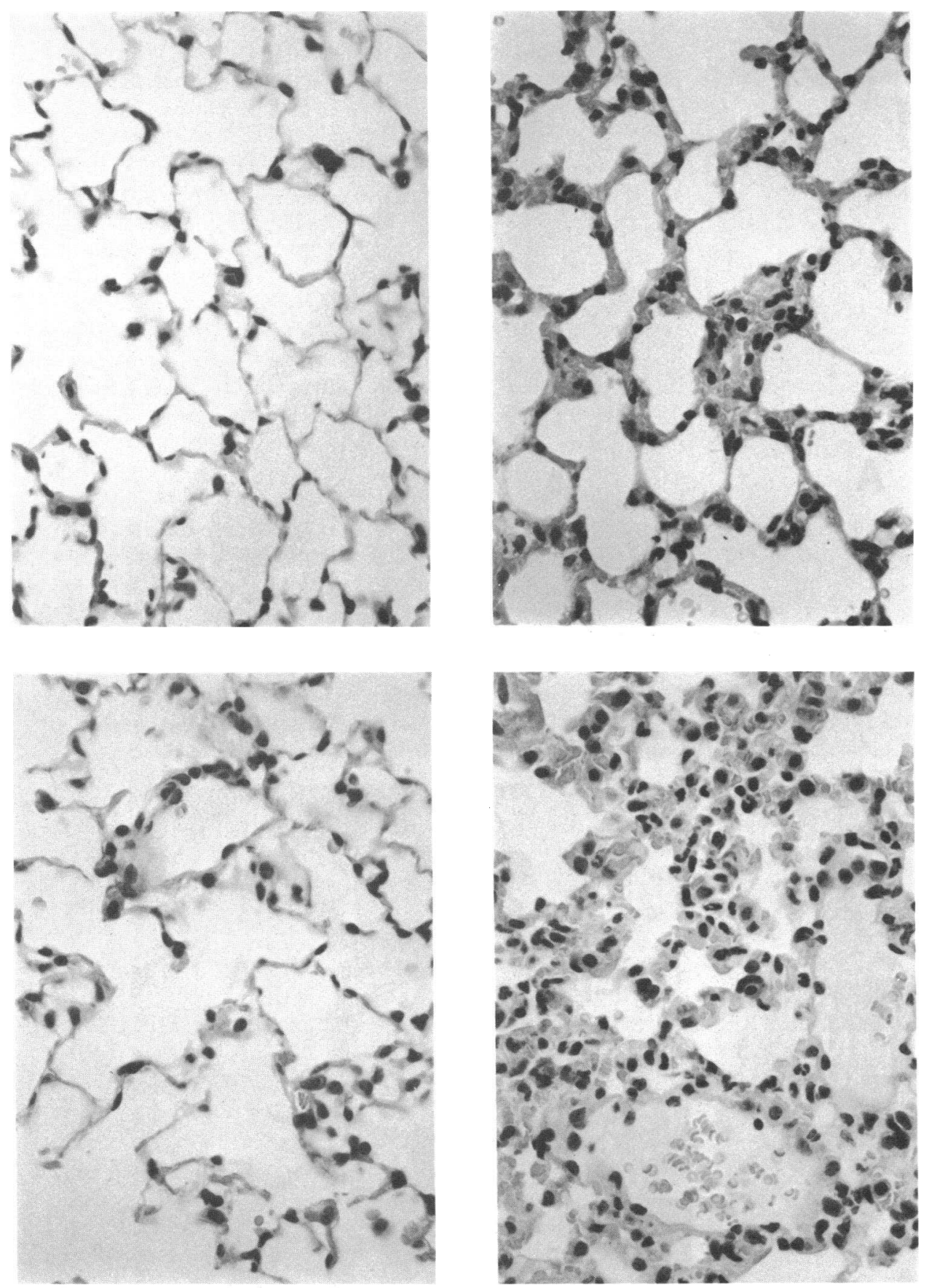

Figure 2. Pulmonary inflammation in $\mathrm{C5}+$ and $\mathrm{C5}$ - mice produced by exposure to hyperoxia. Hematoxylin and eosin stain; original magnification, $\times 320$. (Upper left) Normal lung histology is seen in C5- mice after $60 \mathrm{~h}$ of hyperoxic exposure. (Upper right) Inflammation produced in $\mathrm{C} 5+$ mice after $60 \mathrm{~h}$ of exposure to hyperoxia. There is a suggestion of increased cellularity and widening of the alveolar capillary membrane. (Lower left) The C5- murine lungs begin to show inflammatory changes after $120 \mathrm{~h}$ of hyperoxia. A slight increase in cellularity is noted. (Lower right) After $120 \mathrm{~h}$ of hyperoxia, the C5+ murine lungs show progression of the inflammatory process, with greater cellularity, and a polymorphonuclear leukocyte influx.

to oxygen with age as is noted in some species where newborns are more resistant to hyperoxia than adult animals (19). Lavages were done after $72,120,168$, and $215 \mathrm{~h}$ of exposure to hyperoxia. There were no significant differences in the lavagable neutrophils at the earlier time points. However, at $215 \mathrm{~h}$, the percentage of neutrophils in the $\mathrm{C} 5+$ mice compared with C5- mice was $56.0 \pm 10.1 \%$ vs. $6.4 \pm 4.4 \%(P<0.01)$ and the total leukocyte counts were $19.6 \times 10^{5}$ vs. $8.6 \times 10^{5}$ (Fig. 5 ). Thus, the younger mice also displayed an earlier increase in total leukocyte counts and neutrophils within the lung, but these changes were delayed in the younger animals.

In addition to examination of the total leukocyte counts 

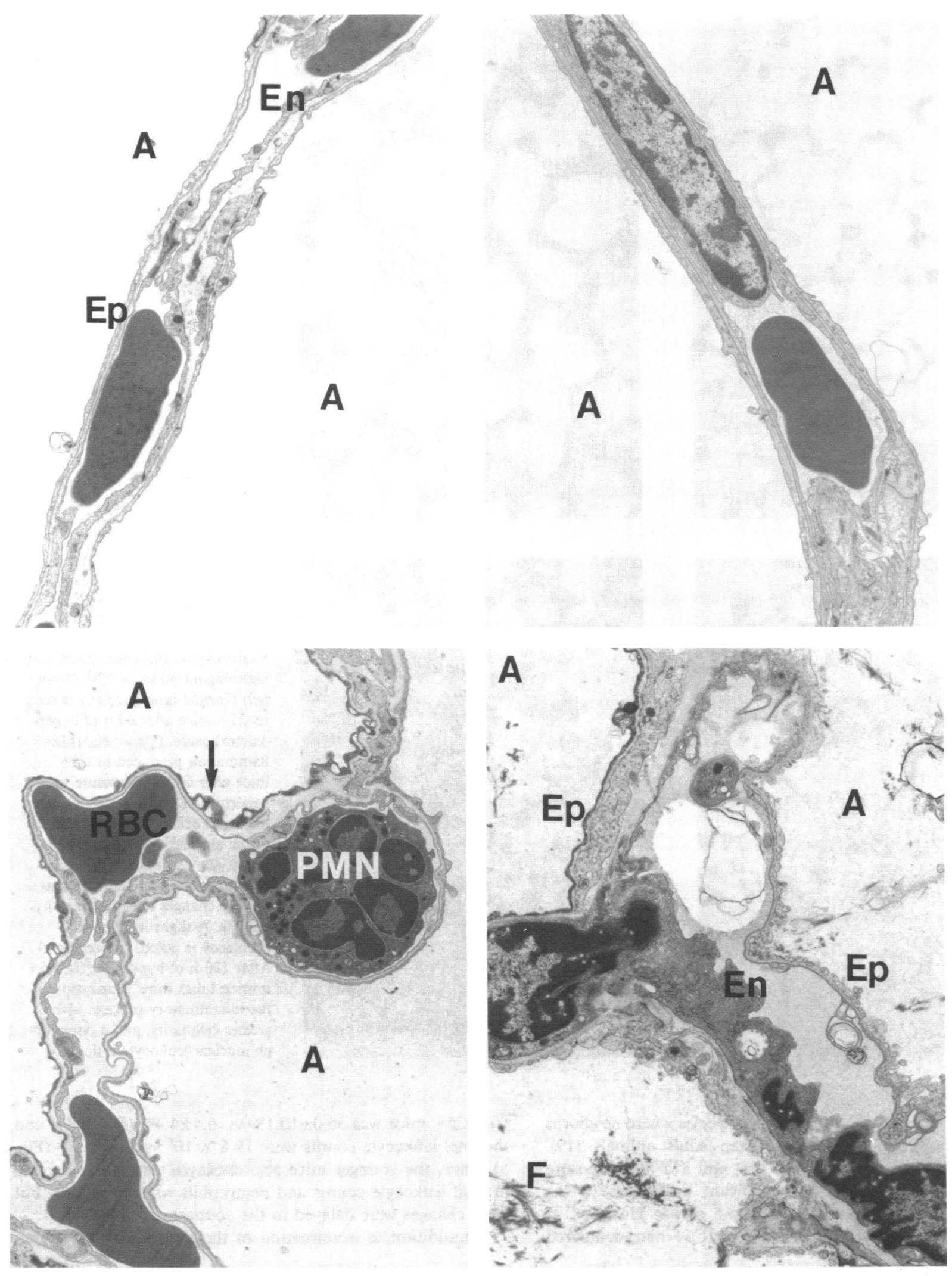

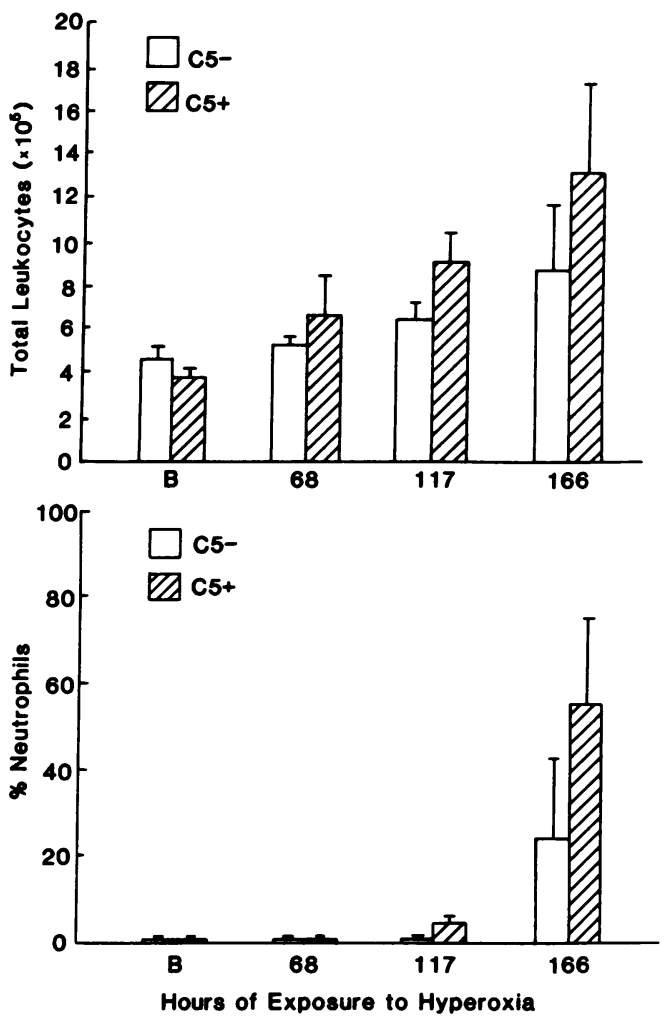

Figure 4. Effect of prolonged exposure to hyperoxia on the total leukocyte counts and percentage of neutrophils in bronchoalveolar lavage fluid of mice greater than $6 \mathrm{mo}$ old. The values expressed are mean $\pm \mathrm{SE}$. The number of mice examined at the time points was eight except at $166 \mathrm{~h}$, where the number of pairs was three. As shown in the top graph, both strains show a significant increase from base line (B) in total leukocytes in BALF at the two latter time points $(P<0.05)$. On the bottom graph where percent neutrophils in the lavages are shown, a significant difference in response between the mice is noted at $117 \mathrm{~h}(P<0.05)$.

and neutrophil counts in the BALF after hyperoxic challenge, the absolute number of mononuclear cells was also determined. When base-line values of mononuclear cells were compared with the absolute number found in BALF after increasing periods of exposure to hyperoxia, it was noted that the mean number of these cells did increase in both strains. However, these increases above base-line values were not statistically significant.

Figure 3. Transmission electron microscopy of lungs of $\mathrm{C5}+$ and C5- mice. Original magnification, $\times 4,600$. (Upper left) The normal alveolar-capillary wall of a C5- mouse not exposed to hyperoxia. The alveoli $(A)$ do not contain cells or fluid. The alveolar epithelium $(E p)$ and capillary endothelium $(E n)$ are thin, and the interstitial space is narrow. Erythrocytes are present in the capillary. (Upper right) Alveolar-capillary wall from a C5- mouse after $5 \mathrm{~d}$ of exposure to hyperoxia. No significant alterations from normal are noted. (Lower left) Section of lung from a C5+ mouse after $5 \mathrm{~d}$ of exposure

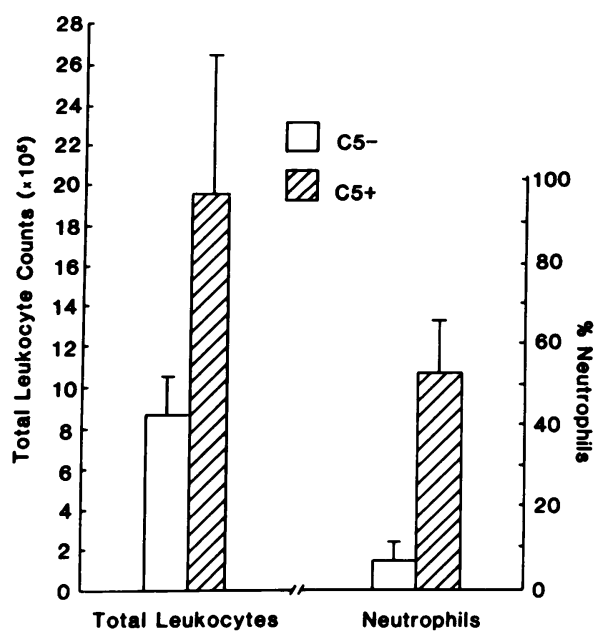

Figure 5. Total leukocyte counts and percent neutrophils in $2 \frac{1}{2}-31 / 2$ mo old C5+ and C5- mice after $215 \mathrm{~h}$ of exposure to hyperoxia. The values are expressed as mean $\pm \mathrm{SE}$. The percentage of neutrophils in the $\mathrm{C} 5+$ mice compared with $\mathrm{C} 5-$ mice was significantly greater $(P<0.01)$.

Morphometrics: alveolar cellularity. From the histology and lavage data, it appeared there was an earlier influx of neutrophils into and through the alveolar-capillary wall in C5 + mice. To determine if this histologic observation could be confirmed in a quantitative manner, a morphometric analysis was done on sections of lung from four $\mathrm{C} 5+$ and four C5- mice after 48,115 , and $140 \mathrm{~h}$ of hyperoxia. As seen in Fig. 6, cellularity within the lungs, which was expressed as total nuclei per field examined, was similar in this experiment until the 140-h time point when increased numbers of cells in C5+ mice were documented. As can be seen in the lower part of the figure, this increase in cellularity was due primarily to an increase in the number of neutrophil nuclei present in the fields.

Transfusion of C5- mice with C5+ plasma. The results of the transfusion experiments are displayed in Fig. 7. C5+ mice subjected to hyperoxia again displayed a cumulative mortality similar to that shown in Fig. 1. The C5- mice transfused with C5+ plasma had a mortality curve very similar to that shown for the mice with normal C5 levels. In contrast, C5- mice transfused with C5- plasma were more resistant to the effects of hyperoxia, as demonstrated by a delay in the onset of mortality. In addition, the difference in cumulative mortality

to $95 \%$ oxygen. The alveoli are filled with fluid, and the alveolarcapillary membrane demonstrates interstitial edema. The alveolarepithelium is darkened on one side of the wall (arrow). A neutrophil $(P M N)$ is present in the capillary. (Lower right) Marked alteration in lung structure in a C5+ mouse exposed to $95 \%$ oxygen for $5 \mathrm{~d}$. Again, the alveoli are filled with fluid that contains fibrin $(F)$. The alveolar epithelium (Ep) appears ruffled in areas, a finding similar to that described by Crapo et al. (14). Interstitial edema is present. 


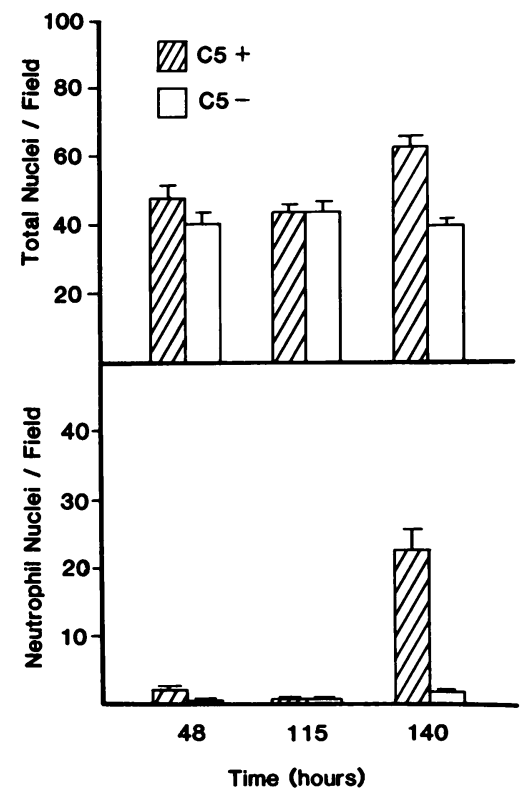

Figure 6. Total nuclei and neutrophil nuclei per field are shown for C5+ and C5- mice after varying times of exposure to 95\% oxygen. Each bar represents four mice and each mouse had eight fields counted. The mean number of alveoli per field ranged from 11 to 13.7. The C5+ mice showed an earlier increase in cellularity in the alveolar walls that was due in part to neutrophil accumulation.

at $196 \mathrm{~h}$ between the $\mathrm{C} 5+$ mice and the $\mathrm{C} 5-$ mice who received $\mathrm{C} 5-$ plasma was significantly different $(P<0.01)$.

Cultures. Although it was felt that animal deaths, lung histologic changes, and abnormal BALF were secondary to oxygen toxicity, cultures of the BALF were done to rule out bacterial infection as an etiology of the observed change. The supernatant from the BALF was plated on blood-agar and observed for growth for $72 \mathrm{~h}$. There were no positive bacterial cultures of lavage fluid in either strain of mice, which suggests that bacterial infection did not cause the observed findings.

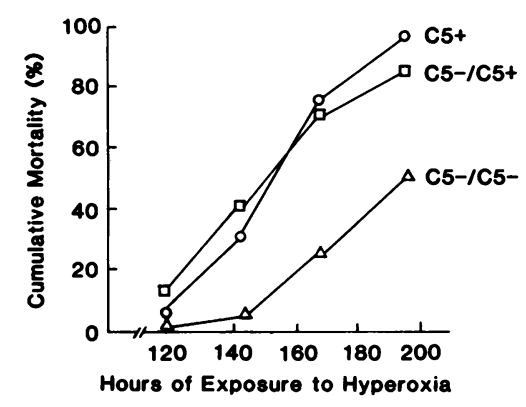

Figure 7. Cumulative mortality in $20 \mathrm{C} 5+$ mice, $20 \mathrm{C5}-$ mice transfused with $\mathrm{C} 5+$ plasma $(\mathrm{C} 5-/ \mathrm{C} 5+)$, and $20 \mathrm{C5}-$ mice transfused with $\mathrm{C5}-$ plasma (C5-/C5-). The transfusion of $\mathrm{C5}+$ plasma into C5- mice accelerated the mortality in the C5- strain.
Peripheral leukocyte counts. To show that the difference in BALF neutrophil counts between $\mathrm{C5}+$ and $\mathrm{C5}-$ mice after hyperoxia was not due to a relative neutropenia in C5- mice, blood was obtained from the retro-orbital plexus for peripheral leukocyte counts and differentials before and after oxygen exposure. In animals exposed to hyperoxia, this was done just before death for BALF analysis. As shown in Table I, baseline neutrophil counts (as well as total leukocytes and differentials) did not differ from each other in six pairs of $\mathrm{C5}+$ and C5- mice. When another group of mice was exposed to a hyperoxic environment for $145 \mathrm{~h}$, the percentage and absolute number of neutrophils in the circulation were increased in both $\mathrm{C} 5+$ and $\mathrm{C} 5-$ mice, with the increase most marked in the C5-deficient mice. As indicated in Table I, the circulating neutrophils in C5+ mice increased from a mean of $817 \pm 108$ / $\mathrm{mm}^{3}$ before exposure to $1,167 \pm 133 / \mathrm{mm}^{3}$ after $145 \mathrm{~h}$ of hyperoxia. This increase was not significant; however, the increase in the C5-deficient mice from a control value of $986 \pm 353$ neutrophils $/ \mathrm{mm}^{3}$ to $2,319 \pm 392 / \mathrm{mm}^{3}$ at $145 \mathrm{~h}$ of hyperoxia was significant $(P<0.05)$. In addition, the difference in circulating neutrophils between the strains was significant at the 145-h time point $(P<0.05)$.

\section{Discussion}

This investigation shows that exposure to hyperoxia is associated with a greater mortality and an earlier influx of neutrophils into the lungs of mice that are C5+ compared with the C5strain. Previous studies have pointed out the inflammatory potential of C5 fragments (C5 fragment with anaphylatoxin activity [C5a] and the C5 fragment formed by removal of the COOH-terminal arginine from C5a [C5a des Arg]), which includes their ability to attract neutrophils and cause oxygen radical production and lysosomal enzyme release from these cells (20). In our laboratory, we found intratracheal instillation of C5a des Arg into rabbits consistently produced marked inflammation that was characterized by neutrophil accumulation, edema, hemorrhage, fibrin formation, and damage to alveolar epithelium (12), changes that can also be seen in hyperoxic lung injury. Since complement components, including C5, are found in BALF (2) and therefore, presumably also in the pulmonary interstitium, it is possible that activation of

Table I. Comparison of Circulating Neutrophils in C5+ and C5-Mice

\begin{tabular}{lll}
\hline & \multicolumn{2}{l}{ Hours of exposure to 95\% oxygen } \\
\cline { 2 - 3 } Mice* & None & $145 \mathrm{H}$ \\
\hline C5 + & $817 \pm 108 \ddagger$ & $1,167 \pm 133$ \\
C5- & $986 \pm 353$ & $2,319 \pm 392$ \\
\hline
\end{tabular}

$* n=6$ for all groups.

$\ddagger$ Results are expressed as mean \pm SEM. 
C5 is involved in neutrophil immigration into the lung in several types of lung injury. Indeed, we have previously shown in murine models that both immune complex instillation into the lung and pulmonary challenge of mice with Pseudomonas aeruginosa are associated with a significantly greater early inflammatory response (neutrophil accumulation) in animals that are C5 sufficient $(7,11)$. This study also shows an earlier, more intense inflammatory response that is associated with a significantly greater mortality in $\mathrm{C} 5+$ mice.

The cleavage of $\mathrm{C} 5$ to its chemotactic fragments in the lung can occur in several ways. For example, it may occur during activation of the proteins in the complement system through either the classical or alternative pathways. Potential stimuli for this type of activation are multiple, but in our experiments, could include exposure of complement components to subcellular membranes from cells that are damaged during the hyperoxic exposure (21). Alternatively, instead of activating the whole complement cascade, the $\mathrm{C} 5$ protein alone could be cleaved to $\mathrm{C5a}$ and/or C5a des Arg by proteinases from macrophages or other cells. Snyderman and co-workers (8) demonstrated that a macrophage proteinase derived from rabbit alveolar macrophages, when incubated with $\mathrm{C} 5$, produced chemotactic activity for neutrophils and macrophages. Ward and Hill (22) showed that incubating C5, but not $\mathrm{C} 3$, with the granule lysates from neutrophils readily produced chemotactic activity. Therefore, the generation of phlogistic fragments from C5 may occur independent of activation of the whole complement sequence.

The differences in mortality and neutrophil influx into the lungs, as shown in Figs. 1 and 4, become obvious after $120 \mathrm{~h}$ of exposure to hyperoxia. As the percentage of neutrophils in the lungs increased, so did the mortality. This is in agreement with Fox and co-workers' observations (15) that increased mortality in rats exposed to hyperoxia is associated with immigration of neutrophils into the lungs. In the same study these authors also reported that depletion of serum complement with $\mathrm{CoF}$ did not alter the mortality or neutrophil immigration into the lungs in rats exposed to hyperoxia. However, this may not have ruled out a role for $\mathrm{C} 5$ in the development of the early inflammatory response to oxygen since the action of $\mathrm{CoF}$ is neither complete nor sustained (23) and its effect on pulmonary complement is unknown. Our results using congenic mice in which the only documented difference is the presence or absence of C5 would suggest that the complement system, and $\mathrm{C5}$ and its fragments in particular, have an important role in producing pulmonary inflammation with this insult. The ability to abolish the differences in mortality in C5+ and C5mice by transfusing $\mathrm{C} 5+$ plasma into the deficient animals not only supports the idea that the only difference in the two strains is the presence or absence of $\mathrm{C5}$, it also suggests that only small amounts of $\mathrm{C} 5$ are needed to produce a pulmonary inflammatory reaction.

The role of the neutrophil in the production of injury with hyperoxia has been addressed in several studies. Shasby and co-workers (24) found that neutrophil depletion in rabbits with nitrogen mustard protected against the harmful effects of exposure to $92-95 \%$ oxygen in that increases in lung edema and depressions in arterial oxygen were less in neutropenic animals. Raj and Bland (25), however, again studying rabbits made neutropenic with nitrogen mustard, were not able to demonstrate any differences in survival or extravascular lung water between neutropenic and normal rabbits. The reasons for the differences in these two studies is currently unexplained. Certainly, the mechanisms involved in producing damage to the lung with hyperoxia are complex and multiple. For example, as recently discussed by Suttorp and Simon (26), oxygen toxicity may be attributed to both the direct damaging effects of highly reactive metabolites of oxygen on cells, and also to the effect of release of toxic oxygen metabolites by neutrophils. Indeed, these authors showed in an in vitro system that three lung cell lines demonstrated enhanced neutrophil-mediated cytotoxicity when the cells were first exposed to sustained hyperoxia. Thus, depending on the relative magnitude of the direct insult to the lung (percentage of inspired oxygen, ambient pressure of the oxygen), the importance of a "secondary" mechanism such as release of oxygen metabolites by neutrophils may be more or less important. In our experiments, as in the work of Fox and co-workers (15), the close association of the neutrophil influx with the onset of mortality suggests that this cell is contributing to the overall pathologic process. It is possible, but currently speculative, that the contribution of the neutrophil is less as the effective concentration of oxygen, which is expressed in terms of fraction inspired and ambient pressure, is increased. Thus, the exact role the neutrophil plays in oxygen toxicity in vivo remains to be clearly defined. Whatever the role of the neutrophil, it does appear that a major part of the toxicity from hyperoxic exposure is related to generation of oxygen radicals (26-30).

The contribution of C5 fragments to the pulmonary inflammatory response may involve more than its interaction with neutrophils, which leads to chemotaxis, oxygen radical production, and lysosomal enzyme release from the cell $(20$, 31). It may also be enhancing pulmonary damage through its action on alveolar macrophages. As described by McCarthy and Henson (32), C5a and C5a des Arg interactions with alveolar macrophages lead to secretion of acid hydrolases and neutral proteases that can cause tissue damage. In addition, C5 fragments may induce the release of a neutrophil chemotactic factor from macrophages (1).

It is important to note that the C5- mice did exhibit an immigration of neutrophils into the lung as shown by both histology and lavage, but to a lesser degree and at a later time than in the $\mathrm{C5}+$ mice. In addition, the ultrastructural changes noted by electron microscopy showed that when alterations occurred, they were the same for both strains of mice and were characterized by increases in both cellular and noncellular components of the interstitium with evidence of injury to alveolar epithelial cells. Similar observations have been made by Crapo and associates in rats (14) and Bonikos and coworkers (33) in mice. The difference noted in our study was 
that the time course over which these events took place was delayed in the C5- strain. The stimulus for neutrophil movement in the absence of C5 may be release of a neutrophil chemotactic factor by alveolar macrophages as has been demonstrated for other stimuli $(1,34,35)$. Indeed, hyperoxia has been demonstrated to cause alveolar macrophages to release chemotoxins for neutrophils (36). The additional release of a neutrophil chemotactic factor from neutrophils that have already immigrated into the lung could augment this neutrophil influx in complement-depleted or -deficient animals (37). These observations that inflammation can be produced in mice that lack $C 5$ point out the inherent redundancy of the inflammatory response, and the ability of the hyperoxic stimulus to produce neutrophil influx by pathways other than C5 cleavage.

The differences in neutrophil accumulation in the lungs of C5+ and C5- mice after prolonged exposure to high concentrations of oxygen was not due to any differences in circulating neutrophils in the two strains of mice before the challenge (Table I). In addition, after $145 \mathrm{~h}$ of hyperoxia, the C5- mice exhibited a significant increase in circulating neutrophils compared with the C5+ strain, but with less pulmonary accumulation of the cell. We believe this indicates that some stimulus leads to mobilization of cells from the marginal pool and/or bone marrow in both strains of mice, but the migration of the cell from the circulation to the lung occurs at an earlier time in the $\mathrm{C} 5+$ animals because of the chemotactic gradient. A similar pattern of differences in circulatory and pulmonary neutrophils between $\mathrm{C} 5+$ and $\mathrm{C5}-$ mice has been noted previously by Larsen and co-workers (7) after intratracheal challenge with Pseudomonas.

In summary, this study shows that the presence of $\mathrm{C5}$ is associated with a greater mortality and an earlier influx of neutrophils into murine lung exposed to hyperoxia. However, in the absence of $\mathrm{C5}$, neutrophils will still immigrate into the lung and hyperoxic damage will occur, but over a more protracted time course. Therefore, these results suggest a role for C5 in the early pulmonary pathology and mortality that are associated with oxygen toxicity.

\section{Acknowledgments}

The authors wish to express their appreciation to Mr. Alan J. Goins and Dr. Norbert Berend for their assistance with the morphometrics, Mrs. Jan Henson for her assistance with the transmission electron microscopy, and Mrs. Georgia Wheeler for her preparation of the manuscript.

This work was supported by grants No. HL-21565 and HL-27063 from the National Institutes of Health.

\section{References}

1. Henson, P. M., K. McCarthy, G. L. Larsen, R. O. Webster, P. C. Giclas, R. B. Dreisin, T. E. King, and J. O. Shaw. 1979. Complement fragments, alveolar macrophages and alveolitis. Am. J. Pathol. 97:93-110.
2. Kolb, W. P., L. M. Kolb, R. A. Wetsel, W. R. Rogers, and J. O. Shaw. 1981. Quantitation and stability of the fifth component of complement (C5) in bronchoalveolar lavage fluids obtained from nonhuman primates. Am. Rev. Respir. Dis. 123:226-231.

3. Robertson, J., J. R. Caldwell, J. R. Castle, and R. H. Waldman. 1976. Evidence for the presence of components of the alternative (properdin) pathway of complement activation in respiration secretions. J. Immunol. 117:900-903.

4. Dreisin, R. B., M. I. Schwarz, A. N. Theofilopoulos, and R. E. Stanford. 1978. Circulating immune complexes in the idiopathic interstitial pneumonias. N. Engl. J. Med. 298:353-357.

5. Henson, P. M., G. L. Larsen, R. O. Webster, B. C. Mitchell, A. J. Goins, and J. E. Henson. 1982. Pulmonary microvascular alterations and injury induced by complement fragments: synergistic effect of complement activation, neutrophil sequestration and prostaglandins. Ann. NY Acad. Sci. 384:287-300.

6. Johnson, K. J., and P. A. Ward. 1974. Acute immunologic pulmonary alveolitis. J. Clin. Invest. 54:349-357.

7. Larsen, G. L., B. C. Mitchell, T. B. Harper, and P. M. Henson. 1982. The pulmonary response of $C 5$ sufficient and deficient mice to Pseudomonas aeruginosa. Am. Rev. Respir. Dis. 126:306-311.

8. Snyderman, R., H. S. Shin, and A. M. Dannenberg. 1972. Macrophage proteinase and inflammation: the production of chemotactic activity from the fifth component of complement by macrophages proteinase. J. Immunol. 109:896-898.

9. Scherzer, H., and P. A. Ward. 1978. Lung and dermal vascular injury produced by preformed immune complexes. Am. Rev. Respir. Dis. 117:551-557.

10. Desai, U., D. L. Kreutzer, H. Showell, C. V. Arroyave, and P. A. Ward. 1979. Acute inflammatory reactions induced by chemotactic factors. Am. J. Pathol. 96:71-83.

11. Larsen, G. L., B. C. Mitchell, and P. M. Henson. 1981. The pulmonary response of $\mathrm{C5}$ sufficient and deficient mice to immune complexes. Am. Rev. Respir. Dis. 123:434-439.

12. Larsen, G. L., K. McCarthy, R. O. Webster, J. Henson, and P. M. Henson. 1980. A differential effect of C5a and C5a des Arg in the induction of pulmonary inflammation. Am. J. Pathol. 100:179192.

13. Pratt, P. C. 1974. Pathology of pulmonary oxygen toxicity. Am. Rev. Respir. Dis. 110(2):51-57.

14. Crapo, J. D., B. E. Barry, H. A. Foscue, and J. Shelburne. 1980. Structural and biochemical changes in rat lungs occurring during exposures to lethal and adaptive doses of oxygen. Am. Rev. Respir. Dis. 122:123-143.

15. Fox, R. B., J. R. Hoidal, D. M. Brown, and J. E. Repine. 1981. Pulmonary inflammation due to oxygen toxicity: involvement of chemotactic factors and polymorphonuclear leukocytes. Am. Rev. Respir. Dis. 123:521-523.

16. Nilsson, U. R., and H. J. Müller-Eberhard. 1967. Deficiency of the fifth component of complement in mice with an inherited complement defect. J. Exp. Med. 125:1-16.

16a.Committee on Care and Use of Laboratory Animals of the Institute of Laboratory Animal Resources. 1978. Guide for the Care and Use of Laboratory Animals. National Institutes of Health, Department of Health, Education, and Welfare, Bethesda, MD. 70 pp.

17. Berend, N., J. L. Wright, W. M. Thurlbeck, G. E. Marlin, and A. J. Woolcock. 1981. Small airways disease: reproducibility of measurements and correlation with lung function. Chest. 79:263-268.

18. Colton, T. 1974. Statistics in Medicine. Little, Brown \& Co., Boston. 129-131, 177-179. 
19. Frank, L., J. R. Bucher, and R. J. Roberts. 1978. Oxygen toxicity in neonatal and adult animals of various species. J. Appl. Physiol. 45:699-704.

20. Webster, R. O., S. R. Hong, R. B. Johnston, and P. M. Henson. 1980. Biological effects of the human complement fragments C5a and C5a des Arg on neutrophil functions. Immunopharmacology. 2:201219.

21. Giclas, P. C., R. N. Pinckard, and M. S. Olson. 1979. In vitro activation of complement by isolated human heart subcellular membranes. J. Immunol. 122:146-151.

22. Ward, P. A., and J. H. Hill. 1970. C5 chemotactic fragments produced by an enzyme in lysosomal granules of neutrophils. $J$. Immunol. 104:535-543.

23. Cochrane, C. G., H. J. Müller-Eberhard, and B. S. Aikin. 1970. Depletion of plasma complement in vivo by a protein of cobra venom: its effect on various immunologic reactions. J. Immunol. 105:55-69.

24. Shasby, D. M., R. B. Rox, R. N. Harada, and J. E. Repine. 1982. Reduction of the edema of acute hyperoxic lung injury by granulocyte depletion. J. Appl. Physiol. 52:1237-1244.

25. Raj, J. U., and R. D. Bland. 1983. Neutrophil depletion does not prevent oxygen-induced lung injury in rabbits. Chest. 83:20S-21S

26. Suttorp, N., and L. M. Simon. 1982. Lung cell oxidant injury. Enhancement of polymorphonuclear leukocyte-mediated cytotoxicity in lung cells exposed to sustained in vitro hyperoxia. J. Clin. Invest. 70:342-350.

27. Autor, A. P., L. Frank, and R. J. Roberts. 1976. Developmental characteristics of pulmonary superoxide dismutase: relationship to idiopathic respiratory distress syndrome. Pediatr. Res. 10:154-158.

28. Bonta, B. W., E. R. Gawron, and J. B. Warshaw. 1977. Neonatal red cell superoxide dismutase enzyme levels: possible role as a cellular defense mechanism against pulmonary oxygen toxicity. Pediatr. Res. 11:754-757.

29. Ehrenkranz, R. A., R. C. Ablow, and J. B. Warshaw. 1978.
Oxygen toxicity: the complications of oxygen use in the newborn infant. Clin. Perinatol. 5:437-450.

30. Frank, L., A. P. Autor, and R. J. Roberts. 1977. Oxygen therapy and hyaline membrane disease: the effect of hyperoxia on pulmonary superoxide dismutase activity and the mediating role of plasma or serum. J. Pediatr. 90:105-110.

31. Goldstein, I. M., D. Roos, H. B. Kaplan, and G. Weissmann. 1975. Complement and immunoglobulins stimulate superoxide production by human leukocytes independently of phagocytosis. J. Clin. Invest. 56:1155-1163.

32. McCarthy, K., and P. M. Henson. 1979. Induction of lysosomal enzyme secretion by alveolar macrophages in response to the purified complement fragments C5a and C5a des Arg. J. Immunol. 123:25112517.

33. Bonikos, D. S., K. G. Bensch, S. K. Ludwin, and W. H. Northway. 1975. Oxygen toxicity in the newborn. The effect of prolonged 100 percent $\mathrm{O}_{2}$ exposure on the lungs of newborn mice. Lab. Invest. 32:619-635.

34. Hunninghake, G. W., J. I. Gallin, and A. S. Fauci. 1978. Immunologic reactivity of the lung: the in vivo and in vitro generation of a neutrophil chemotactic factor by alveolar macrophages. Am. Rev. Respir. Dis. 117:15-23.

35. Valone, F. H., M. Franklin, F. F. Sun, and E. J. Goetzl. 1980. Alveolar macrophage lipoxygenase products of arachidonic acid: isolation and recognition as the predominant constituents of the neutrophil chemotactic activity elaborated by alveolar macrophages. Cell. Immunol. $54: 390-401$.

36. Harada, R. N., C. M. Bowman, R. B. Fox, and J. E. Repine. 1982. Alveolar macrophage secretions: initiators of inflammation in pulmonary oxygen toxicity? Chest. 81:52-54.

37. Ford-Hutchinson, A. W., M. A. Bray, M. V. Doig, M. E. Shipley, and M. J. H. Smith. 1980. Leukotriene B, a potent chemokinetic and aggregating substance released from polymorphonuclear leukocytes. Nature (Lond.). 286:264-265. 